\title{
THEORETICAL INVESTIGATION OF STEERING ABILITY OF MOVEMENT OF ASYMMETRIC SWATH HEADERAND-TRACTOR AGGREGATE
}

\author{
Volodymyr Bulgakov ${ }^{1}$, Semjons Ivanovs ${ }^{2}$, Valeriy Adamchuk ${ }^{3}$, Janusz Nowak ${ }^{4}$ \\ ${ }^{1}$ National University of Life and Environmental Sciences of Ukraine, Ukraine; \\ ${ }^{2}$ Latvia University of Life Sciences and Technologies, Latvia; ${ }^{3}$ National Scientific Centre \\ "Institute for Agricultural Engineering and Electrification" of Ukraine, Ukraine; \\ ${ }^{4}$ University of Life Sciences in Lublin, Poland \\ semjons@apollo.lv
}

\begin{abstract}
In order to ensure the required steering ability of the asymmetric swath header (windrower) machineand-tractor aggregate, it is necessary to determine the design and kinematic parameters of the undercarriage of the aggregating tractor and the supporting wheels of the trailed swath header (windrower), which will provide the required level of stable and controlled movement. The aim of this investigation is to perform numerical simulation on the PC of the previously obtained new analytical dependencies of a plane-parallel movement of the asymmetric swath header aggregate and to determine optimal parameters for the steering ability of its movement. By the results of the numerical simulation, it has been determined that a necessary condition providing a high level of steerability of the movement is setting the left support wheel of the trailed swath header (windrower) to the left of the hitching device at value $-0.2 \mathrm{~m}$, and its simultaneous additional loading with a weight of 100-120 kg. This will help reduce the turning angles of the trailed swath header in a horizontal plane. To ensure high steering ability of the movement of this aggregate, it is necessary to optimize the internal air pressure in the pneumatic tires of its support wheels.
\end{abstract}

Keywords: asymmetric swath header, steering, simulation.

\section{Introduction}

When operating any machine-and-tractor aggregate, an important factor is its steering ability. In addition, for the agricultural machine aggregates, especially for the mobile harvesting aggregates, one of the necessary conditions for their operation is the steering ability of their movement in a horizontal plane [1].

By the steering ability of any complex mechanical system one should understand its ability to react adequately and in a timely manner to the control actions (of the operator or the automatic control system, when it concerns mobile systems), while keeping the necessary stability parameters of its functioning that ensure qualitative execution of the prescribed functions of the technological process [2]. The issues of the stability and steering ability of the movement of agricultural machines and machine aggregates have been dealt with in the fundamental works by P. Vasilenko, L. Gyachev, etc. [3-5]. In these studies, the indicators of stability and steering ability of the movement that are most important for the machine-and-tractor aggregates are estimated on the basis of constructed computational mathematical models of such aggregates describing their plane-parallel movement.

However, the steering ability of the movement of mobile agricultural machine-and-tractor aggregates has not yet been investigated fully enough. Especially it concerns mobile asymmetric machine-and-tractor aggregates, for which, as it is believed, the insufficient steering ability of the movement will necessarily be compensated by the operator (the tractor driver), who controls the aggregating source of power. It should be particularly emphasised that a swath header (windrower), asymmetrically hitched to the rear of the aggregating wheeled tractor, creates such an impact upon the source of power that makes the operator carry out control actions regularly and continuously that require his utmost attention and quick response to the rapidly changing traffic conditions (to ensure the necessary path of the movement). This not only lowers significantly the comfort of the tractor operator, but also makes him reduce essentially the operating speed of such an aggregate, which also substantially reduces the quality and productivity of work [6; 7]. Up to the present time, studies in this direction have been carried out not sufficiently fully, and, most importantly, no new computational mathematical models have been constructed, which would then be used in full for efficient studying of the stability and steering ability of the movement. This is why a necessity arises to study the steering ability of the movement of a mobile asymmetric windrower-and-tractor aggregate by using analytical methods of the amplitude-frequency analysis, providing a possibility to determine such kinematic and 
design parameters that will ensure conditions for maximum and efficient steering ability of its movement in a horizontal plane.

The aim of the investigation is to determine optimal steering ability parameters of the movement of an asymmetric windrower-and-tractor aggregate on the basis of numerical simulation of the previously obtained new analytical dependencies on the PC.

\section{Materials and methods}

For an asymmetric agricultural machine-and-tractor aggregate the control impact is the turning angle $\alpha$ of the front driven wheels of the aggregating tractor. In contrast to random factors affecting the stability of the movement of a machine-and-tractor aggregate, its stability is also influenced by the control impact, although it is carried out purposefully to maintain the necessary parameters of the performed technological process. From the numerous parameters that characterise a steady movement of the asymmetric harvesting machine-and-tractor unit, we selected three main parameters having the most significant effect upon the indicated stability of movement. These are the lateral displacement $X_{S}$ of the centre of mass of the aggregating wheeled tractor, the relative turning angle (bearing) $\varphi$ of its longitudinal axis, as well as the deviation angle $\beta$ of the hitched swathheader from the longitudinal axis of the tractor in a horizontal plane. In addition, the movement of the machine-and-tractor aggregate under consideration will be considered as stable, if the values of each of them do not exceed the allowed limits prescribed by the agrotechnological or some other requirements.

We have constructed a computational mathematical model of the plane-parallel movement of an asymmetric windrowing machine-and-tractor aggregate, consisting of a wheeled aggregating tractor to the rear hitch of which a swath header is attached [8]. First of all, for this asymmetric scheme of the machine-and-tractor aggregate, an equivalent scheme was built, presented in Fig. 1.

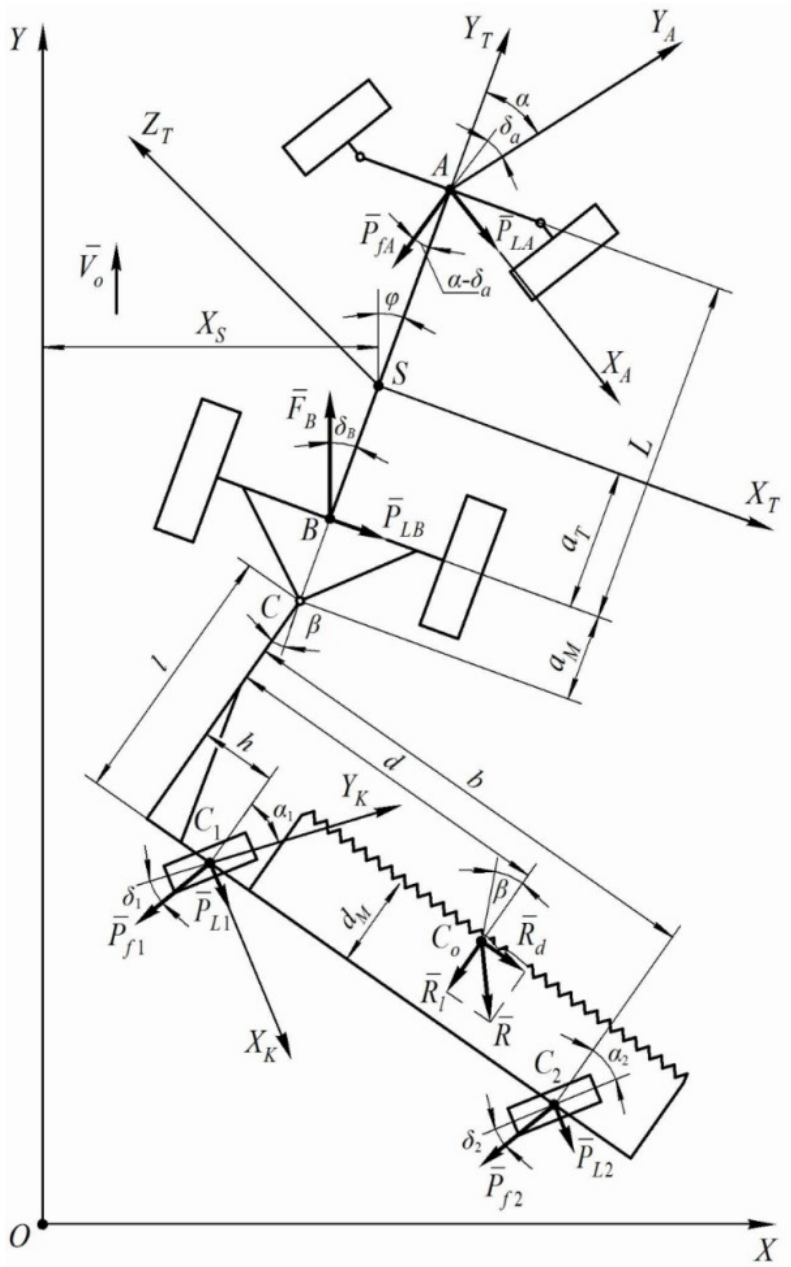

Fig. 1. Equivalent scheme of asymmetric windrowing machine-and-tractor aggregate 
Therefore, in addition to the power and kinematic characteristics, as well as the parameters $X_{S}, \varphi$ and $\beta$, characterizing the stability of the movement, the differential equations of the plane-parallel movement of the particular machine-and-tractor aggregate must necessarily include also the control parameters. In this case it is the turning angle $\alpha$ of the front driven wheels of the aggregating tractor. Such a mathematical model of a plane-parallel movement will make it possible to simulate the impact of the turning angle $\alpha$ of the driven wheels of the tractor upon the stability parameters of the movement $X_{S}, \varphi$ and $\beta$, which will provide a possibility to determine such design and kinematic parameters of the aggregate that the real amplitude-frequency and phase-frequency characteristics of the above-mentioned three parameters are close to the desired (preset) ones, when its front driven wheels perform the turning angle $\alpha$ (i.e., the control impact). And this, in the end, will ensure not only high steerability of traffic, but also high-quality execution of the technological process, as well as the operation reliability and safety of this harvesting machine-and-tractor aggregate.

According to this equivalent scheme, generalised coordinates were chosen and, on the basis of the initial equations of the dynamics in the Lagrange form of the second kind, a system of differential equations for the plane-parallel movement of an asymmetric harvesting machine-and-tractor aggregate was compiled, which then, through Laplace transforms [9], made it possible to pass over to the system of algebraic equations having the following form:

$$
\left.\begin{array}{l}
K_{11} \cdot X_{S}(s)+K_{12} \cdot \varphi(s)+K_{13} \cdot \beta(s)=F_{11} \cdot \alpha(s)+F_{12} \cdot 1(s), \\
K_{21} \cdot X_{S}(s)+K_{22} \cdot \varphi(s)+K_{23} \cdot \beta(s)=F_{21} \cdot \alpha(s)+F_{22} \cdot 1(s), \\
K_{31} \cdot X_{S}(s)+K_{32} \cdot \varphi(s)+K_{33} \cdot \beta(s)=F_{31} \cdot \alpha(s)+F_{32} \cdot 1(s),
\end{array}\right\}
$$

where

$$
\begin{aligned}
& K_{11}=A_{11} \cdot s^{2}+A_{12} \cdot s ; \\
& K_{12}=A_{13} \cdot s+A_{14} \text {; } \\
& A_{13}=\frac{\left(k_{A}+P_{f A}\right) \cdot\left(L-a_{T}\right)+\left(F_{B}-k_{B}\right) \cdot a_{T}}{V_{o}} ; \\
& K_{13}=A_{15} \text {; } \\
& A_{14}=F_{B}-k_{A}-k_{B}-P_{f A} \text {; } \\
& K_{21}=A_{24} \cdot s \text {; } \\
& A_{15}=P_{K R} \text {; } \\
& K_{22}=A_{21} \cdot s^{2}+A_{22} \cdot s+A_{23} \text {; } \\
& A_{21}=J_{S} \text {; } \\
& K_{23}=A_{25} \text {; } \\
& K_{31}=A_{36} \cdot s \text {; } \\
& K_{32}=A_{34} \cdot s+A_{35} \text {; } \\
& K_{33}=A_{31} \cdot s^{2}+A_{32} \cdot s+A_{33} \text {; } \\
& A_{22}=\frac{\left(k_{A}+P_{f A}\right) \cdot\left(L-a_{T}\right)^{2}+\left(k_{B}-F_{B}\right) \cdot a_{T}^{2}}{V_{o}} ; \\
& A_{23}=-A_{13} \cdot V_{o} \text {; } \\
& F_{11}=f_{11} \text {; } \\
& A_{24}=A_{13} \text {; } \\
& F_{21}=f_{21} \text {; } \\
& A_{25}=-P_{K R}\left(a_{T}+a_{M}\right) \text {; } \\
& F_{32}=f_{31} \text {; } \\
& F_{12}=F_{22}=F_{31}=0 \text {; } \\
& f_{11}=k_{A} \text {; } \\
& f_{21}=\left(L-a_{T}\right) \cdot k_{A} \text {; } \\
& f_{31}=R_{l} \cdot d+P_{f 1} \cdot h+ \\
& +P_{f 2} \cdot b-\alpha_{1} \cdot l \cdot k_{1}-\alpha_{2} \cdot l \cdot k_{2} \\
& A_{11}=M_{T} \text {; } \\
& A_{12}=\frac{k_{A}+k_{B}+P_{f A}-F_{B}}{V_{o}} \text {; } \\
& A_{31}=J_{C} \text {; } \\
& A_{32}=\frac{l \cdot\left[\left(k_{1}+P_{f 1}\right) \cdot\left(l^{2}+h^{2}\right)^{\frac{1}{2}}+\left(k_{2}+P_{f 2}\right) \cdot\left(l^{2}+b^{2}\right)^{\frac{1}{2}}\right]}{V_{o}} ; \\
& A_{33}=R_{l}\left(l-d_{M}\right)+l\left(k_{1}+k_{2}+P_{f 1}+P_{f 2}\right) \text {; } \\
& A_{34}=\frac{l \cdot\left(a_{T}+a_{M}\right) \cdot\left(k_{1}+k_{2}+P_{f 1}+P_{f 2}\right)}{V_{o}} \\
& A_{35}=l\left(k_{1}+k_{2}+P_{f 1}+P_{f 2}\right) \text {; } \\
& A_{36}=-\frac{A_{35}}{V_{o}}
\end{aligned}
$$


$1(s)$ - single-step change in the input parameter;

$M_{T}$ and $J_{S}$ - respectively, mass of the wheeled aggregating tractor and its inertia moment relative to the centre of mass;

$k_{A}, k_{B}$ - drag coefficients of the pneumatic tires of the wheels, respectively, of the front and rear axles of the tractor;

$k_{1}, k_{2}$ - drag coefficients of the pneumatic tires, respectively, of the left-side and two right-side supporting wheels of the trailed swath header;

$\alpha_{1}, \alpha_{2}$ - angles of setting of the left-side and right-side wheels of the swath header;

$J_{C}$-inertia moment of the swath header relative to the vertical axis passing through point

$C$;

$V_{o}$ - speed of the movement of the aggregate;

$L, \alpha_{T}, a_{M}, l, h, b, d$ and $d_{M}$ - design parameters shown in an equivalent scheme; designations of the external forces and the points of their application are also shown in the equivalent scheme (Fig. 1).

The characteristics were studied using as a model a harvesting asymmetric machine-and-tractor aggregate composed from a wheeled aggregating tractor MTZ-82 and a trailed swath header ZVP-6, which performs the technological process of collecting winter wheat into swaths. After compilation of the program and the numerical solution on the PC, a possibility appeared to study analytically the movement of this asymmetric windrowing machine-and-tractor aggregate in a horizontal plane and to estimate its steering ability.

\section{Results and discussion}

On the basis of the results of numerical simulation on the PC, it was found that in case the working speed $V_{o}$ of the asymmetric windrowing machine-and-tractor aggregate is increased to $2.5 \mathrm{~m} \cdot \mathrm{s}^{-1}$, the way how the aggregating wheeled tractor performs the variations of the turning angle $\alpha$ of its driven wheels improves. The actual amplitude-frequency characteristics depend little on the frequency of changes in the control impact, and they approach the desired characteristic (Fig. 2). At $V_{o} \approx 2.5 \mathrm{~m} \cdot \mathrm{s}^{-1}$ they practically correspond to it. At a speed $V_{o}$ greater than $2.5 \mathrm{~m} \cdot \mathrm{s}^{-1}$, the windrowing machine-and-tractor aggregate, as a dynamic system, performs a control impact with over control (up to $60 \%$ ), which, in this case, is not desirable. Analysis of the phase-frequency characteristics (Fig. 3) shows that under any of the considered speed conditions within the range of control impact variations $0-0.8 \mathrm{~s}^{-1}$, the aggregating wheeled tractor changes its course with a delay, the average value of which being only $0.8 \mathrm{~s}$. At the same time, when $\omega>1.2 \mathrm{~s}^{-1}$, the phase shift increases to $6.28 \mathrm{rad}$. As a result, when the aggregating tractor performs a control impact with a frequency of only $1.2 \mathrm{~s}^{-1}$, the delay of its reaction will already be more than $5 \mathrm{~s}$. From the point of view of satisfactory steerability, this phenomenon is obviously not desirable either. In view of what was said above, a conclusion suggests itself that the higher is the speed of the operational movement of the trailed swath header, the lower is the frequency, at which it is necessary to perform a turn of the driven wheels of the wheeled aggregating tractor.

Besides the speed $V_{o}$ of the movement of the aggregate, more or less a significant effect upon the nature of the control impact performed by the machine-and-tractor aggregate is exerted only by the drag coefficients $k_{A}$ and $k_{B}$ of the respective front driven and rear driving pneumatic wheels of the source of power, i.e. of the aggregating wheeled tractor. And this basically applies only to the amplitude-frequency characteristics. As $k_{A}$ increases, they rise (Fig. 4), which is desirable and completely logical, since at a higher value of this drag coefficient of the pneumatic tires of the front driven wheels of the aggregating tractor, it performs more accurately the control impact.Since the trailed swath header is closer to the rear driving wheels of the source of power, its rear axle is more sensitive to the tractive resistance of the trailed swath header than the front axle. It is this that can explain the fact that in case when the value of the coefficient $k_{B}$ is increased, the accuracy of the control impact performed by the aggregating tractor is undesirably reduced (Fig. 5).

However, the value of this decrease is so small that it can practically be neglected. With the aggregating tractor of integral configuration, the "centre of mass" is closer to the front driven wheels. As a result, this allows it, though not so much, but in principle to perform the control impact better than for the source of power of the classical configuration. At the same time, the difference between 
the compared amplitude-frequency and the phase-frequency characteristics is so small that it can be ignored.

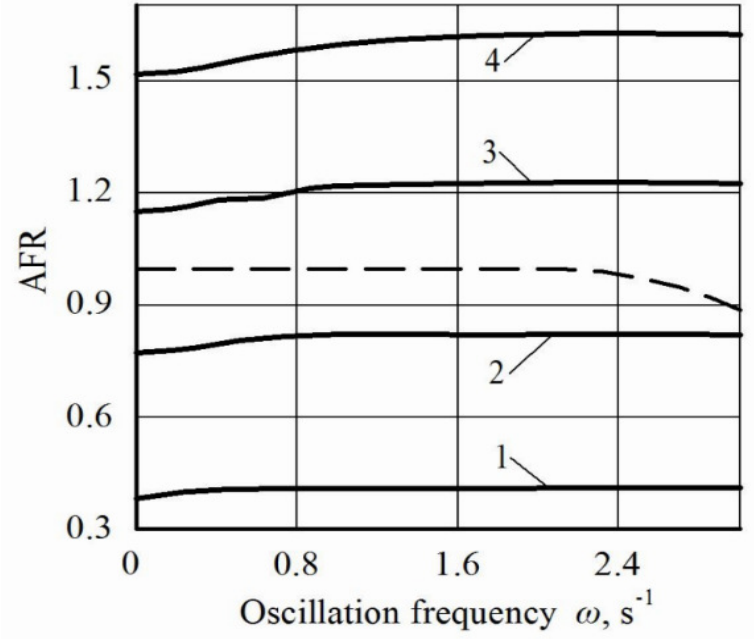

Fig. 2. Desired (- - - ) and actual (-) amplitude-frequency characteristics of turning angle (bearing) $\varphi$ of aggregating tractor when it performs turning angle $\alpha$ of its driven wheels (the control impact) at different speeds of its movement: $1-V_{o}=1.0 \mathrm{~m} \cdot \mathrm{s}^{-1} ; 2-V_{o}=2.0 \mathrm{~m} \cdot \mathrm{s}^{-1}$; $3-V_{o}=3.0 \mathrm{~m} \cdot \mathrm{s}^{-1} ; 4-V_{o}=4.0 \mathrm{~m} \cdot \mathrm{s}^{-1}$

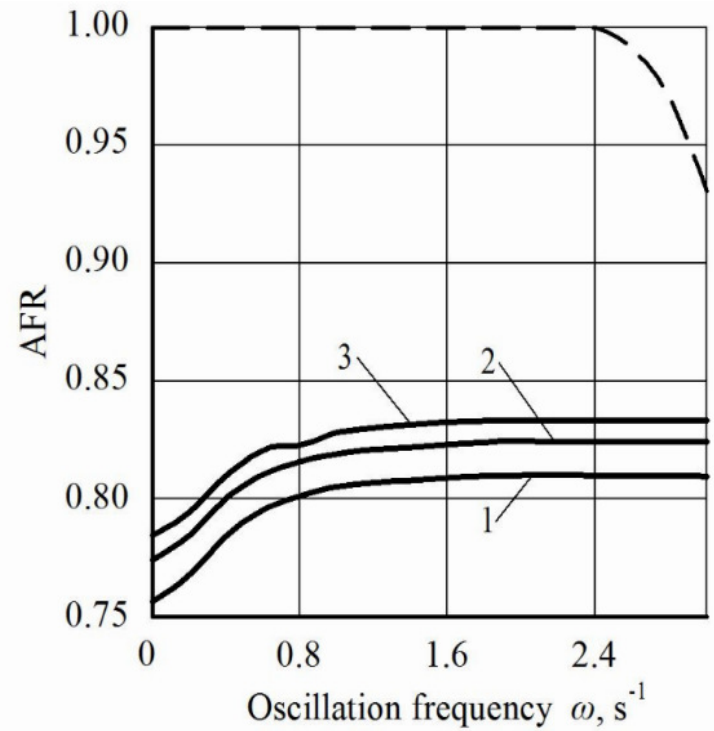

Fig. 4. Desired (- - -) and actual (-) phasefrequency characteristics of turning angle (bearing) $\varphi$ of aggregating tractor when it performs control impact at different drag coefficients of pneumatic tires of its front driven wheels: $1-k_{A}=61 \mathrm{kN} \cdot \mathrm{rad}^{-1}$;

$2-k_{A}=81 \mathrm{kN} \cdot \mathrm{rad}^{-1} ; 3-k_{A}=101 \mathrm{kN} \cdot \mathrm{rad}^{-1}$

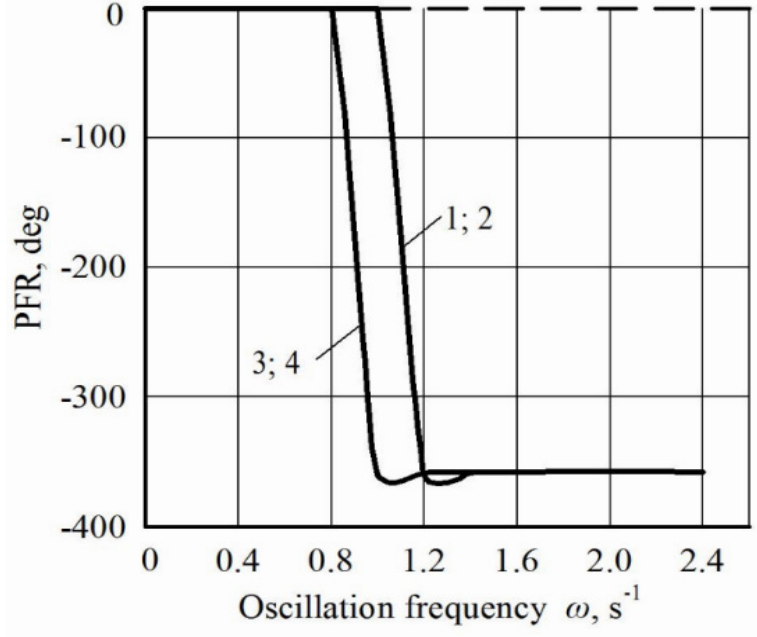

Fig. 3. Desired (- - - ) and actual (-) phasefrequency characteristics of turning angle (bearing) $\varphi$ of aggregating tractor when it performs turning angle $\alpha$ of its driven wheels (the control impact) at different speeds of its movement: $1-V_{o}=1.0 \mathrm{~m} \cdot \mathrm{s}^{-1}$;

$2-V_{o}=2.0 \mathrm{~m} \cdot \mathrm{s}^{-1} ; 3-V_{o}=3.0 \mathrm{~m} \cdot \mathrm{s}^{-1}$; $4-V_{o}=4.0 \mathrm{~m} \cdot \mathrm{s}^{-1}$

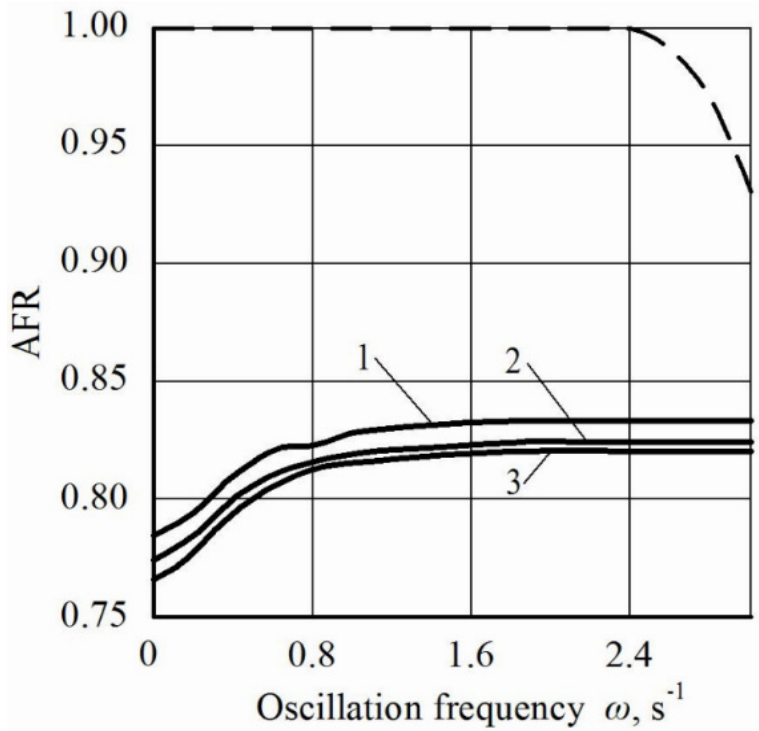

Fig. 5. Desired (- - - ) and actual (-) amplitude-frequency characteristics of turning angle (bearing) $\varphi$ of aggregating tractor when it performs control impact at different drag coefficients of pneumatic tires of its rear driving wheels: $1-k_{B}=100 \mathrm{kN} \cdot \mathrm{rad}^{-1}$;

$2-k_{B}=125 \mathrm{kN} \cdot \mathrm{rad}^{-1} ; 3-k_{B}=150 \mathrm{kN} \cdot \mathrm{rad}^{-1}$

In practice, the energy sources of both configurations can be considered equivalent with respect to the performance of the control impact by them in the form of the turning angle $\alpha$ of the front driven wheels. Let us consider further the impact of the parameters of the swath header machine-and-tractor 
aggregate upon the turning angle $\beta$ of its trailed header in a horizontal plane. It is quite clear that increase in the speed $V_{o}$ of the operational movement of this machine-and-tractor aggregate, as well as increase in the tractive resistance $R_{l}$ of the trailed swath header, lead to the increase in the angle $\beta$ of its deviation in a horizontal plane. Moreover, the value of the tractive resistance $R_{l}$ depends in a corresponding way not only on the resistance of the grain massif but also on value $V_{o}$. As during the operation of other trailed machines and tools, this dependence at velocities greater than $1.5 \mathrm{~m} \cdot \mathrm{s}^{-1}$ is nonlinear. The nature of the change in the transfer function with respect to a single impact in the form of a change in the turning angle of the left-side and two right-side support wheels of the swath header, the offset of its left wheel of and the vertical load on it with respect to the variations of the deviation angle $\beta$ of the header in a horizontal plane $W(s)$ shows that such parameters of the aggregating tractor as the mass $M_{T}$, inertia moment $J_{S}$, longitudinal base $L$, drag coefficients $k_{A}$ and $k_{B}$ of the tires of the front driven and the rear driving wheels, respectively, as well as the longitudinal coordinate $\alpha_{T}$ of the "centre of mass" exert week impact upon the variations of the deviation angle $\beta$ of the trailed swath header in a horizontal plane.

To the design parameters of the trailed swath header, which unambiguously determine the reduction of this parameter, primarily refer:

- inertia moment $J_{C}$;

- length of the hitch bar $l$;

- offset of the left supporting wheel $h$;

- drag coefficient $k_{1}$ of the pneumatic tires of the left supporting wheel;

- angle of setting $\alpha_{1}$ of the left supporting wheel;

- drag coefficient $k_{2}$ of the pneumatic tires of the two right-side supporting wheels;

- angle of setting $\alpha_{2}$ of the two right-side supporting wheels.

Using the results of the numerical simulation on a PC, let us analyse the impact of these parameters of the swath header upon the stability of its movement and steering ability of the movement of this asymmetric harvesting machine-and-tractor aggregate. Increase in the inertia moment $J_{C}$ of the trailed swath header in a horizontal plane reduces, though insignificantly, the angle of its deviation $\beta$. Nevertheless, since the growth of $J_{C}$ is possible at the expense of the increase or the size of the swath header, or its mass, it is not expedient to use both ways as options in order to increase the stability of the movement of the trailed swath header in a horizontal plane.

It has been found out by theoretical simulation that in case the length $l$ of the hitch bar of the swath header is increased, its deviation in a horizontal plane decreases. But, since this deviation is insignificant (from $6^{\circ}-$ at $l=3.0 \mathrm{~m}$ to $4^{\circ}-$ at $l=4.5 \mathrm{~m}$ ), it is not advisable, in our opinion, to recommend such a way of increasing the stability of the operational movement of the trailed swath header either. More than that, increasing the length $l$ of the hitch bar may adversely affect the turning ability of the entire asymmetric harvesting machine-and-tractor aggregate.

Installation of the left supporting wheel of the swath header to the left of its hitch bar (in this case value $h$ becomes negative) also has insignificant impact upon the reduction of angle $\beta$. However, such a design solution does not create problems for its practical implementation, it does not affect the nonproductive consumption of time, etc., and therefore it can be recommended, in principle, for application. Moreover, if this wheel is loaded with additional weight of $100-120 \mathrm{~kg}$.

It has been established by analytic calculations on the PC that the tire drag coefficient $k_{2}$ of the two right-side supporting wheels of the trailed swath header exerts more intense impact upon angle $\beta$ of its deviation in a horizontal plane than coefficient $k_{1}$ (Fig. 6). Nevertheless, in both cases, their impact upon the magnitude of value $\beta$ is such that it can be taken into account only as an additional measure interacting with the basic measure. As the last ones there are such design parameters of the trailed swath header as the installation angles of its left $\left(\alpha_{1}\right)$ and the two right $\left(\alpha_{2}\right)$ supporting wheels. Analysis of the results of mathematical simulation shows that, as in the case with the drag coefficients $k_{1}$ and $k_{2}$ of the pneumatic tires of the supporting wheels, the angle $\alpha_{2}$ has a more intense impact upon the decrease of the angle $\beta$ (Fig. 7).

However, the greatest effect takes place not at a separate, but a simultaneous setting of the left and the two right supporting wheels of the swath header at an angle to the direction of the movement. For 
instance, at $l=3.4 \mathrm{~m} ; h=0.2 \mathrm{~m} ; P_{f 1}=0.3 \mathrm{kN} ; R_{l}=7 \mathrm{kN} ; k_{1}=25 \mathrm{kN} \cdot \mathrm{rad}^{-1} ; k_{2}=50 \mathrm{kN} \cdot \mathrm{rad}^{-1}$ and the travel speed of the windrowing machine-and-tractor aggregate $V_{o}=3.0 \mathrm{~m} \cdot \mathrm{s}^{-1}$ angle $\beta$ decreases from $5^{\circ}$ - at $\alpha_{1}=\alpha_{2}=0^{\circ}$, to $1^{\circ}-$ at $\alpha_{1}=\alpha_{2}=8^{\circ}$ (see Fig. 7).

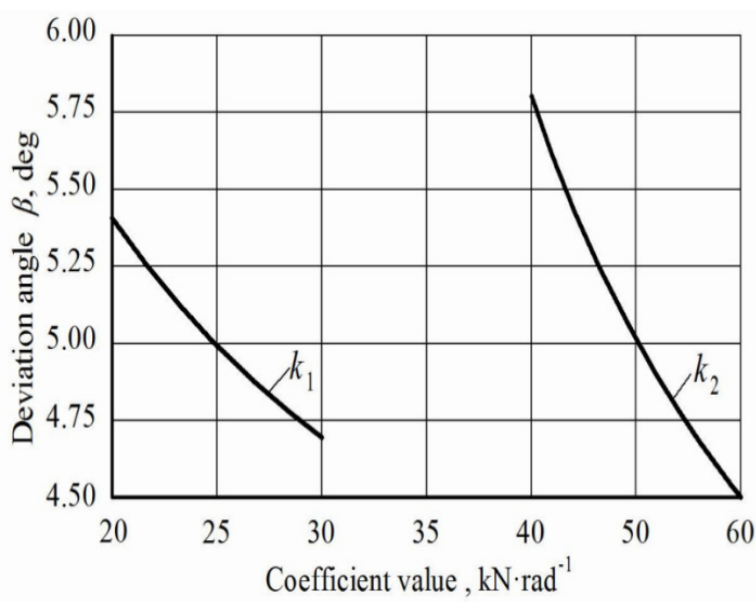

Fig. 6. Impact of drag coefficients of pneumatic tires of left $\left(k_{1}\right)$ and two right $\left(k_{2}\right)$ supporting wheels of swath header

(windrower) upon its deviation angle $\beta$ in horizontal plane

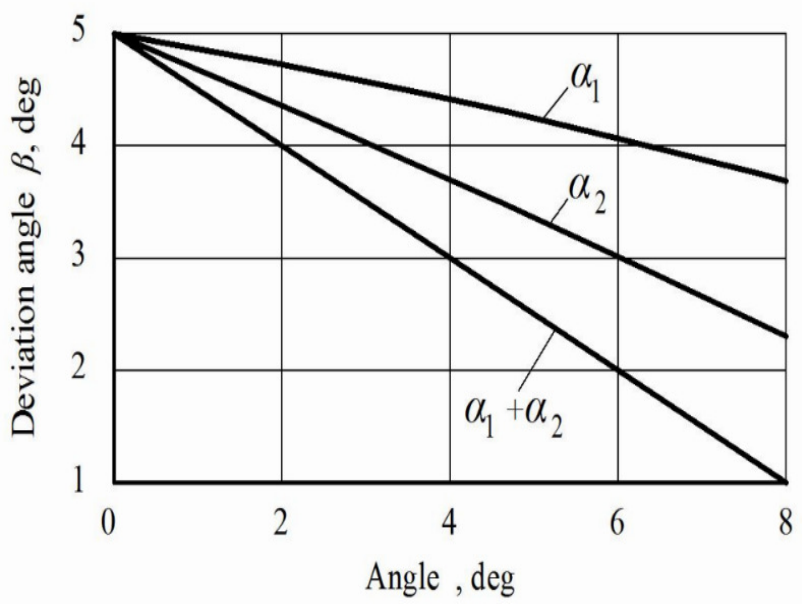

Fig. 7. Impact of installation angles of left $\left(\alpha_{1}\right)$,right $\left(\alpha_{2}\right)$ and simultaneously of left and right $\left(\alpha_{1}+\alpha_{2}\right)$ supporting wheels of trailed swath header (windrower) upon its deviation angle $\beta$ in horizontal plane

If, in addition, to install the left supporting wheel of the trailed swath header to the left of the hitch bar (in this case $h$ assumes a negative value $h=-0.2 \mathrm{~m}$ ), to load it with additional mass of $100 \mathrm{~kg}$, and, by changing the internal air pressure in the pneumatic tires of the supporting wheels, to ensure the values of the coefficients at the level $k_{1}=30 \mathrm{kN} \cdot \mathrm{rad}^{-1}$ and $k_{2}=65 \mathrm{kN} \cdot \mathrm{rad}^{-1}$, then the trailed swath header in the aggregate with a wheeled tractor of a classical configuration will move in a horizontal plane practically without deviation.

Further increasing of any of the design parameters analysed above (and especially $\alpha_{1}$ and $\alpha_{2}$, deviation of the swath header is possible during its aggregation. Then the angle $\beta$ assumes a negative value, which is, in principle, also not desirable. In fact, this leads to practically the same negative consequences as the possible delay of the trailed swath header.

\section{Conclusions}

1. In order to ensure the necessary steering ability of the movement of an asymmetric swath header (windrower) machine-and-tractor aggregate, increase in the speed of its movement during the execution of the technological process has to be accompanied by a corresponding decrease in the frequency of the turns of the front driven wheels of the aggregating tractor.

2. Installation of the left supporting wheel of the swath header to the left of the hitch bar simultaneously with its additional loading (ballasting) with the weight of $100-120 \mathrm{~kg}$, promotes the reduction of the turning angles $\beta$ of the trailed swath header in a horizontal plane.

3. The conducted analytical calculations on the PC show that the greatest impact upon the variations of the turning angle $\beta$ of the trailed swath header in the horizontal plane is exerted by the installation angle $\alpha_{2}$ of its right-side supporting wheels.

4. 4. Calculation of definite parameters on the basis of the results of analytical studies, executed on the PC, which ensure the steering ability of the movement of a trailed swath header, indicated to the necessity to install the left supporting wheel of the swath header to the left of the hitch bar at a value of $\mathrm{h}=-0.2 \mathrm{~m}$, and to its additional loading with a weight not less than $100 \mathrm{~kg}$. Besides, by changing the internal air pressure in the pneumatic tires of the supporting wheels of the trailed swath header, it is necessary to set the values of the coefficients at a level $k_{1}=30 \mathrm{kN} \cdot \mathrm{rad}^{-1}$ and $k_{2}=65 \mathrm{kN} \cdot \mathrm{rad}^{-1}$. This will provide a possibility for the trailed swath header to move almost without deviations in a horizontal plane. 


\section{References}

[1] Bhatia N.P., Szegő G. P. Stability theory of dynamical systems. Springer, 2002, 250 p.

[2] Smith M., Wisten M. A continuous day-to-day traffic assignment model and the existence of a continuous dynamic user equilibrium. Annals of Operations Research, 60 (1), 1995, pp. 59-79.

[3] Василенко П. Введение в земледельческую механику (Introduction to agricultural mechanics). Kiev, 1996, 136 p. (In Ukrainian)

[4] Гячев Л.О прямолинейном движении колесного трактора при боковом расположении навесной жатки (About rectilinear movement of a wheeled tractor with a laterally mounted reaper).Mechanization and electrification of agriculture, 6, 1979, pp. 40-42. (In Russian)

[5] Гячев Л. Stability of the movement of agricultural machines and aggregates (Устойчивость движения сельскохозяйственных машин и агрегатов). Mechanical engineering, Moscow, 1981, 206 p. (In Russian)

[6] Bulgakov V., Ivanovs S., Adamchuk V., Nadykto V. Theoretical investigation of turning ability of machine and tractor aggregate on basis of ploughing and intertilling wheeled tractor. Engineering for Rural Development, Proceedings, Vol.15, 2016, pp.1077-1084.

[7] Viesturs D., Kopiks N. Investigations in suitability of fleet of combines for timely harvesting. Engineering for rural development, Proceedings, Vol.15, 2016, pp. 681-686.

[8] Bulgakov V., Pascuzzi S., Nadykto V., Ivanovs S. A mathematical model of the plane-parallel movement of an asymmetric machine and tractor aggregate. Journal of Agricultural Engineering. Vol. 49,No 1, 2018, pp. 258-271.

[9] Dreizler R.M., Ludde C.S. Theoretical Mechanics. Springer, Berlin,2010

[10]Гячев Л.Динамика машинно-тракторных и автомобильных агрегатов (Dynamics of the machine and tractor and automobile aggregates). Monograph, Rostov-on-Don, Russia, 1976, 192 p. (In Russian) 